\title{
Batch and Flow Asymmetric Catalysis for the Synthesis of Chiral Active Pharmaceutical Compounds ${ }^{+}$
}

\author{
Maurizio Benaglia \\ Dipartimento di Chimica, Università degli Studi di Milano, 20122 Milano, Italy; maurizio.benaglia@unimi.it \\ † Presented at Symmetry 2017-The First International Conference on Symmetry, Barcelona, Spain, \\ 16-18 October 2017.
}

Published: 3 January 2018

Keywords: enabling technologies; flow chemistry; catalytic reactors; organocatalysis; stereoselective reactions

Continuous-flow systems have emerged as a powerful technology for performing chemical transformations and have recently attracted attention also for the preparation of chiral APIs (active pharmaceutical ingredients).

Recently developed technology-assisted stereoselective reactions will be discussed, including reactions of nitroacrylates under MW irradiation and organocatalyzed reactions in alternative reaction media (Deep Eutectic Solvents). Some stereoselective transformations have been performed in chiral organocatalytic reactors (packed-bed and monolithic) under continuous flow conditions. Recent developments will be presented, also highlighting the possibility to perform organocatalytic reactions in (micro)-mesoreactors and to synthesize in flow-mode chiral intermediates of pharmaceutical interest. Preliminary results of stereoselective catalytic reactions in 3D-printed reactors will also be briefly highlighted.

(C) 2018 by the author. Licensee MDPI, Basel, Switzerland. This article is an open access article distributed under the terms and conditions of the Creative Commons Attribution (CC BY) license (http://creativecommons.org/licenses/by/4.0/). 